\title{
3D Product Development for Loose-Fitting Garments Based on Parametric Human Models
}

\author{
Sybille KRZYWINSKI, Jana SIEGMUND, Ellen WENDT \\ TU Dresden, Institute of Textile Machinery and High Performance Material Technology (ITM), Germany \\ DOI: $10.15221 / 15.010$ http://dx.doi.org/10.15221/15.010
}

\begin{abstract}
Researchers and commercial suppliers worldwide pursue the objective of achieving a more transparent garment construction process that is computationally linked to a virtual body, in order to save development costs over the long term. The current aim is not to transfer the complete pattern making step to a 3D design environment but to work out basic constructions in 3D that provide excellent fit due to their accurate construction and morphological pattern grading (automatic change of sizes in 3D) in respect of sizes and body types. After a computer-aided derivation of 2D pattern parts, these can be made available to the industry as a basis on which to create more fashionable variations.
\end{abstract}

Keywords: Parametric 3D models, computer-aided 3D product development, loose-fitting garments, 2D pattern, grading in 3D

\section{Introduction}

Despite the global division of labour and the associated outsourcing of manufacture, garments are still mainly developed in Germany or Western Europe. The reason is the know-how in pattern making that has been gained over decades, the knowledge of fashion desires and functional requirements, the long-term safeguarding of product quality and the proximity to domestic consumers. In order to ensure the competitiveness of the European garment industry also in the future, the results from research must be practically relevant and be implemented faster in product development.

In recent years the German fashion industry has made great investments to obtain up-to-date information about body proportions and body dimensions as a result of the size survey SizeGERMANY [SIZ 13] and, based on these, to develop a size system that reflects the customer's current body dimensions and finds acceptance in the industry. To be able to provide the majority of the German population with industrially manufactured garments of perfect fit, 10 sizes (related to girth) were defined for men in five body heights and five body shapes (250 variants in total) and 15 sizes (related to girth) were defined for women in three body heights and three hip shapes (135 variants). This work has been largely completed. The stated number of sizes and variants clearly illustrates what great requirements resulting from the variety of human body shapes the garment industry has to cope with. Added to this is the abundance of different textile materials.

Although detailed information on dimensions and shapes are now available to support the model designer, the basic procedure in practice has hardly changed in the last five years. No lasting revision of the $2 \mathrm{D}$ design specifications has yet been made to take the sizing survey data into account. To date, most basic constructions (e.g. for blouses/shirts, jackets, dresses, skirts, trousers) are based on just a small number of body dimensions. Body shape parameters are implemented by relying on so called proportional dimensions and empiricism and are thus not reproducible. This procedure is encountered worldwide and is reflected in the country-specific standard reference works of pattern making (e.g. [KOP 91], [STA 91], [KIR 95], [NAK 95], [ROS 04], [LIU 05], [MAT 06], [ALD 08], [ARM 09], [MUE 13], [UNI 13]).

Virtual fit simulation in application of software solutions such as Modaris V7 [LEC 13], VIDYA [ASS 13], V-Stitcher [BRO 13] or Optitex PDS [OPT 13] is also just starting to be comprehensively used in the industry.

These simulation programs permit a digital 3D visualisation of the garment by virtual sewing combined with an approximate consideration of the properties of the textile materials used. Poor fit can thus be recognised early without sewing or by sewing only a reduced number of prototypes. However, here again, constructional deficiencies are eliminated in an iterative process in the 2D CAD environment. 
While other industries, e.g. the automotive and machine construction industries, have massively promoted the transition to 3D methods for years, the associated benefits of linking aesthetical and technical design during the whole design chain have hardly been exploited in the garment industry. The causes are the extreme complexity of the human shape (geometry) and the problem that garment construction constitutes an idealisation of the body shape. In addition, designing in 3D requires model designers with extended knowledge. The greatest challenge of the transition to a new CAD system is the application method. The designers have become familiar with 2D systems over many years and have been trained intensively how to handle these. A full transition to a 3D method currently seems not to be implementable in the fashion industry because, on the one hand, the new generation of engineers trained at such systems just starts making its way into the companies. On the other hand, the software solutions are not yet mature enough for application-specific needs so that they do not allow efficient working methods in practical use.

Despite all deficiencies of the 2D design method which demands enormous expert knowledge in order to translate the design into well-fitting garments in a $2 \mathrm{D}$ design environment with as few iterations as possible, this procedure is still dominant in the industry.

In order to make better use of the research results, the link between digital 3D body shape data, 3D basic constructions and 2D pattern making is being investigated.

Model designers can then continue to use their usual software tools, but build their modelling steps on basic constructions that are automatically generated based on 3D body shape data or use these data to check their designs.

Therefore, solutions are being worked out to exploit the present development progress, yet allowing their adaptation to the current work environment by special tools and methods, and thus to facilitate the transition without overburdening the staff by completely new procedures.

\section{General approach}

While the models of basic sizes (e.g. German sizes 38 to 46 for women's wear) are often designed with good success, insecurities and the number of necessary iteration loops increase for the sets of sizes derived by pattern grading to cover the variety of sizes and body shapes. Due to the enormous time pressure placed on design departments in industrial practice, typically only few sizes are tested for fit using prototypes and live models. Poor fit and dissatisfied customers or a considerable return rate $(40 \%$ to $70 \%)$ are the deplorable result.

Due to the enormous variety of models in loose-fitting women's wear and some considerable design ease in relation to the body to suit the fashion style, it makes no sense to aim at a complete 3D design.

Available 3D CAD systems are awkward to use when drawing wide skirts, sleeves, flounces or gathers and the like. The translation of such features in 2D would be complicated since the surfaces produced can only be imaged flat with considerable distortions and would therefore not result in useful pattern parts.

Researchers in this field worldwide thus agree that, in 3D, it only makes sense to design constructions with necessary wearing or comfort-related ease in relation to the body, and based on these, to automatically derive 2D patterns with proper fit. The boundary conditions apply to all basic constructions (bodices with and without darts for dresses/coats, blouses/jackets as wells as skirts and trousers). It would thus be great progress if model designers could have access to a wide size spectrum derived from body shape data and tested for fit.

\subsection{Development of scalable virtual female mannequins}

Working out 3D based basic constructions for women's wear first requires the development of virtual mannequins of variable shape that allow scaling for sizes and body shapes.

The starting point is a polygon model of German size 38 (see Fig. 1 left). 

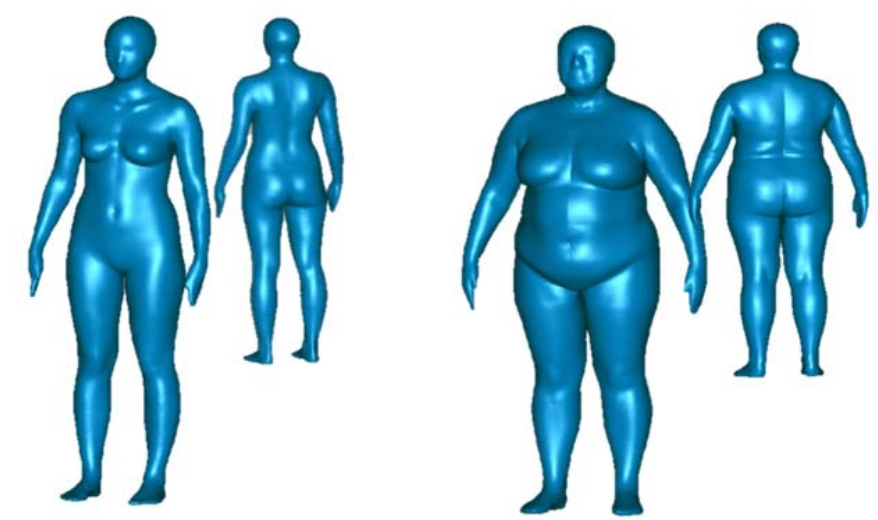

Fig. 1 Polygon data: left German size 38, right German size 54, source HIT

For the body-conforming mapping of these and further sizes (e.g. German size 54 in Fig. 1 right) by means of spline surfaces (spline surfaces are more suitable for CAD environments), it is of enormous importance to determine the number of cutting planes in the horizontal and vertical directions as well as further dividing lines.

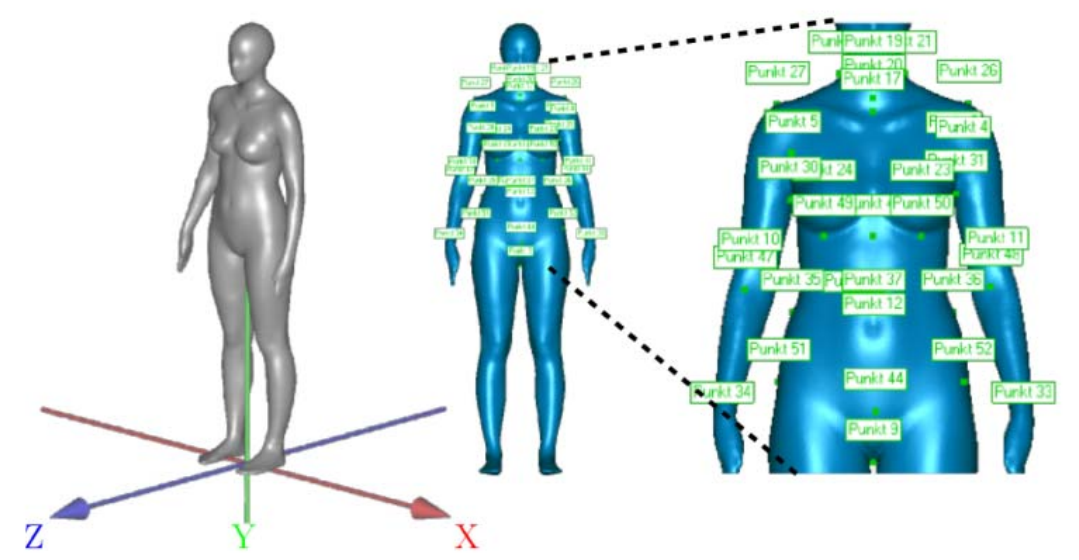

Fig. 2 Feature points on the body to determine body dimensions

To position the cutting planes, the feature points on the body (Fig. 2) are first used to determine the body dimension lines (chest girth, waist girth, ... Fig. 3 red lines) or measured lengths (shoulder width) on the body. If these are not sufficient, further curves are determined to allow accurate mapping of the body shape by CAD surfaces (Fig. 3 - yellow lines). The intersections of these lines are defined as feature points and used for size-specific scaling. These points are assigned "increment values" in the form of $x, y, z$ coordinates and stored in a database so that scaling can be automatic. The feature points are linked by spline curves or surfaces to map the body surface.
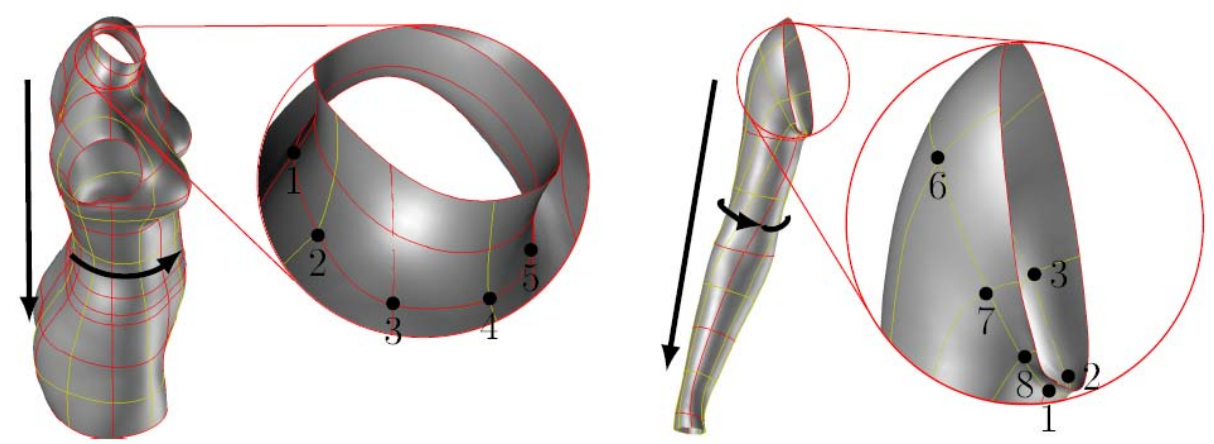

Fig. 3 Surface distribution (red - body dimension lines, yellow - additional lines for surface construction) - feature points

By linking the CAD data with an Excel sheet where the point information is stored, it is thus possible to generate a different size at the touch of a key in a computer-aided operation (Fig. 4). To be absolutely certain that the considerable change of curve and surface shapes is accurately mapped, all CAD data were verified using medium-height mannequins of available sizes (Fig. 5). 

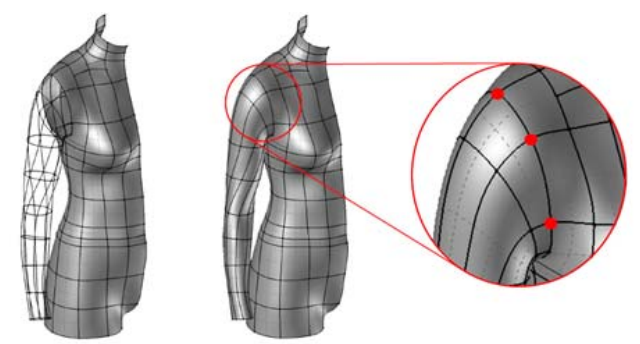

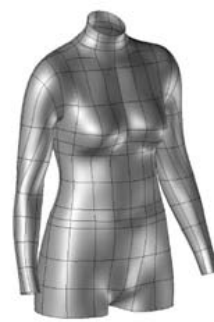

38

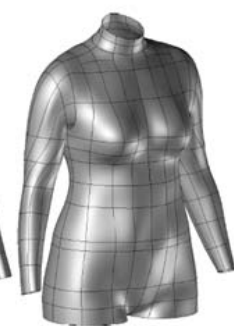

42

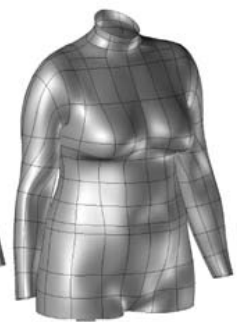

46

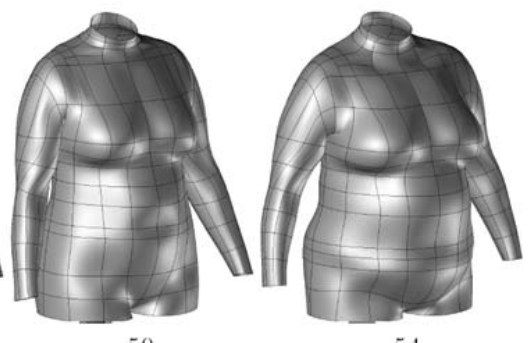

50

54

Fig. 4 Top: Arm-chest junction; Bottom: computed CAD models of the different sizes

In a false-colour display, Figure 5 shows the differences determined between the medium-height polygon model of German size 54 and the computed spline surfaces. The shape congruence of such complex geometries is considered to be very positive.
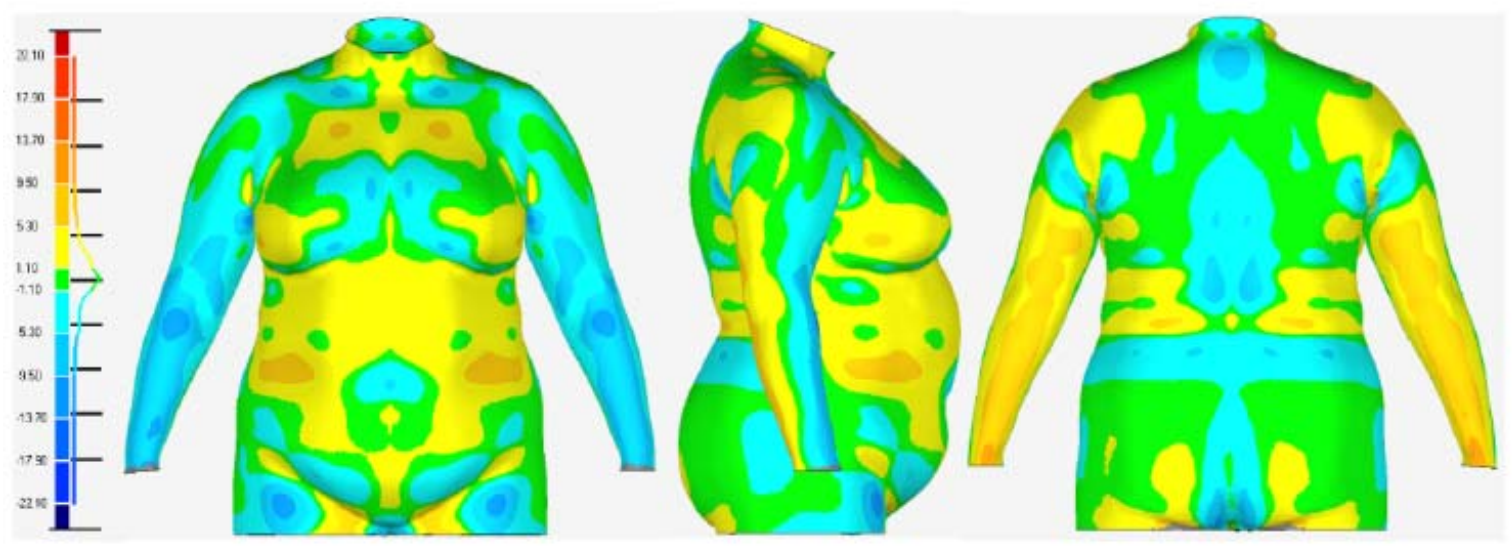

Fig. 5: Check of shape accuracy based on the polygon model and the spline surfaces in German size 54

\subsection{Development of the construction methodology for basic constructions of women's wear}

Our own investigations [HLA 11], [KRZ 13], [HLA 13] and literature research [WAN 02], [PET 06], [KIM 07], [AND 08], [LIU 10], [HUA 12], [KUZ 13] have shown that even with basic constructions the garment is not placed on the body in the form of offset curves or surfaces. To get a feeling for how garments hug the body or at what distance from the body they should be positioned, it is possible to simulate 3D basic constructions of the model size (e.g. German size 38) on the virtual mannequin. Since the flexural softness of the fabric has a significant effect on drapability and thus on the space between garment and body, a rather stiff fabric is chosen for the simulation in order to limit folds. Another possibility is to scan test subjects in well-fitting garments. In both cases the result is a polygon model. This can then be used to determine the cutting curves in the planes that are significant for the construction. In the case investigated the basic construction is sewn following a construction rule of Müller\&Sohn [MUE 13] with only little allowance added to the construction lines (see Table 1) (Fig. 6).

Table 1: Allowances added to the construction lines

\begin{tabular}{|c|c|c|}
\hline Name & Initials & Allowance (tight) [cm] \\
\hline Back width & $\mathrm{BW}$ & 0 \\
\hline Armhole diameter & $\mathrm{AD}$ & 2.5 \\
\hline Chest width & $\mathrm{CW}$ & 0.5 \\
\hline
\end{tabular}



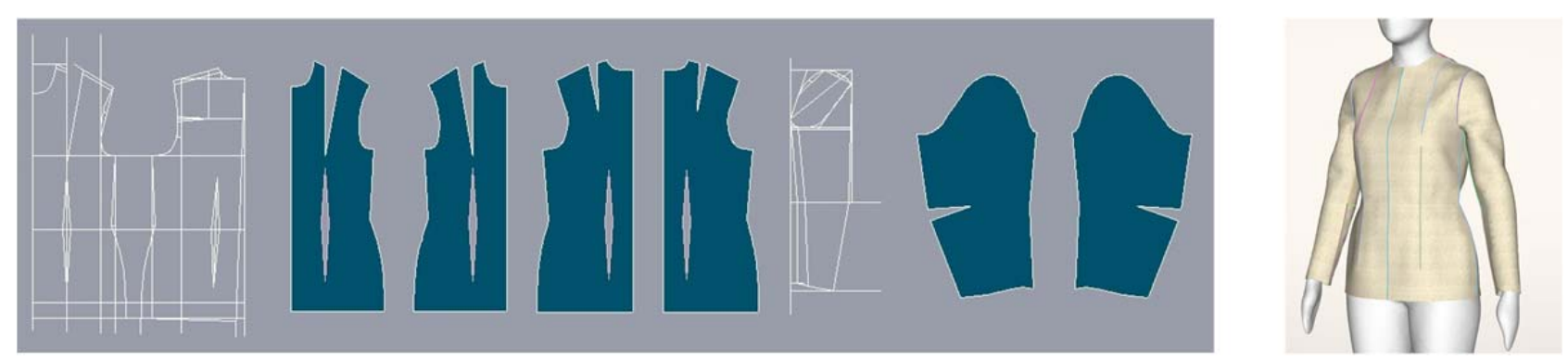

Fig. 6: Left: Basic blouse construction in German size 38 (tight), Right: Fit simulation in Modaris V7

Fig. 7 shows the relationship determined between blouse and body based on the cutting curves. The curves are smoothed a bit, and in the next step, they must be described mathematically, stored in the construction database and designed using parameters in order to be able to change and adapt the ease allowance automatically. To maintain the relation to the body, in the best case all feature points of every cutting curve on the body are used since the size-specific scaling is already stored there. How many and what points are used depends on the complexity of the curve (Fig. 7).
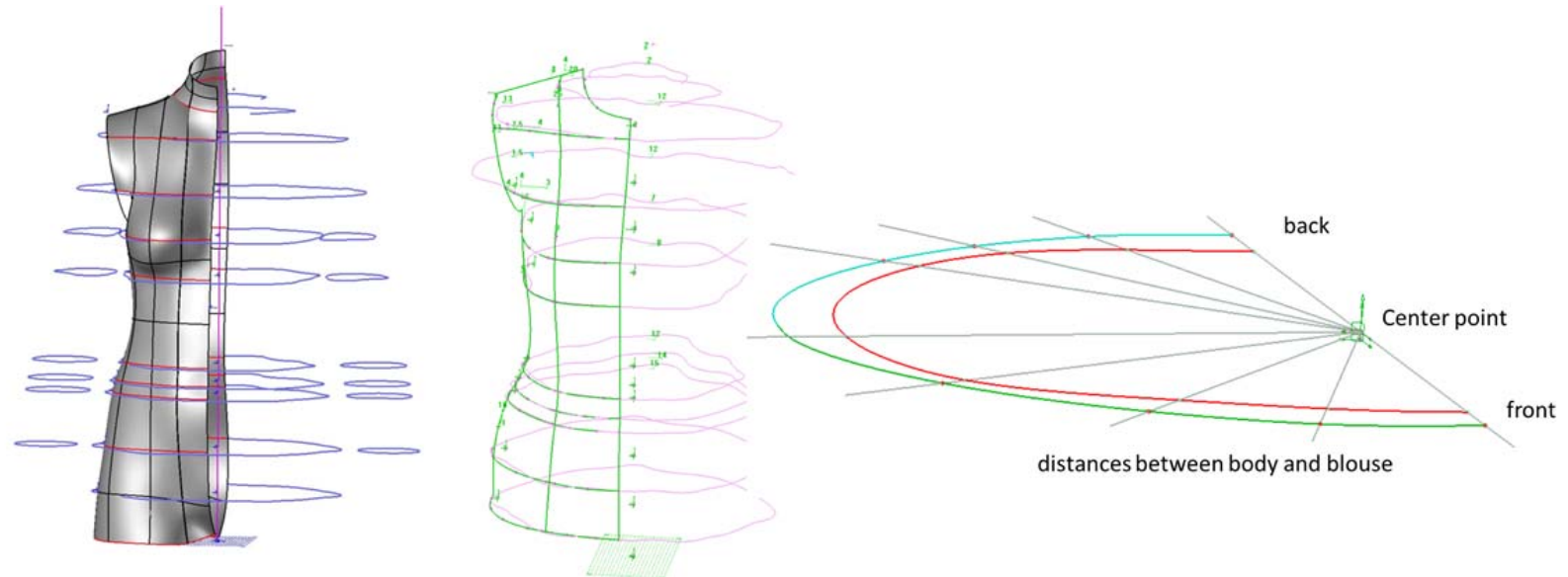

Fig. 7: Left: Cutting curve on body (red) / blouse (blue), Centre: Curves for blouse construction (green), Right: Parameters for flexible design of the ease allowance

To eliminate the need to approximate the surfaces for describing the garment shape by using a multitude of regular patches, freeform surfaces are used. These can be generated with any 3D CAD software on the basis of the described curve construction. The implementation of the computational change in ease allowance, e.g. for translating the basic construction of a dress into that of a coat and this over the desired size spectrum, sets high scientific requirements.

The bodice and sleeve constructions are worked out, scaled and tested for fit in separate assemblies. To do so, the interdependence of armhole curves and sleeve curves is defined and determined with positional accuracy (Fig. 8).
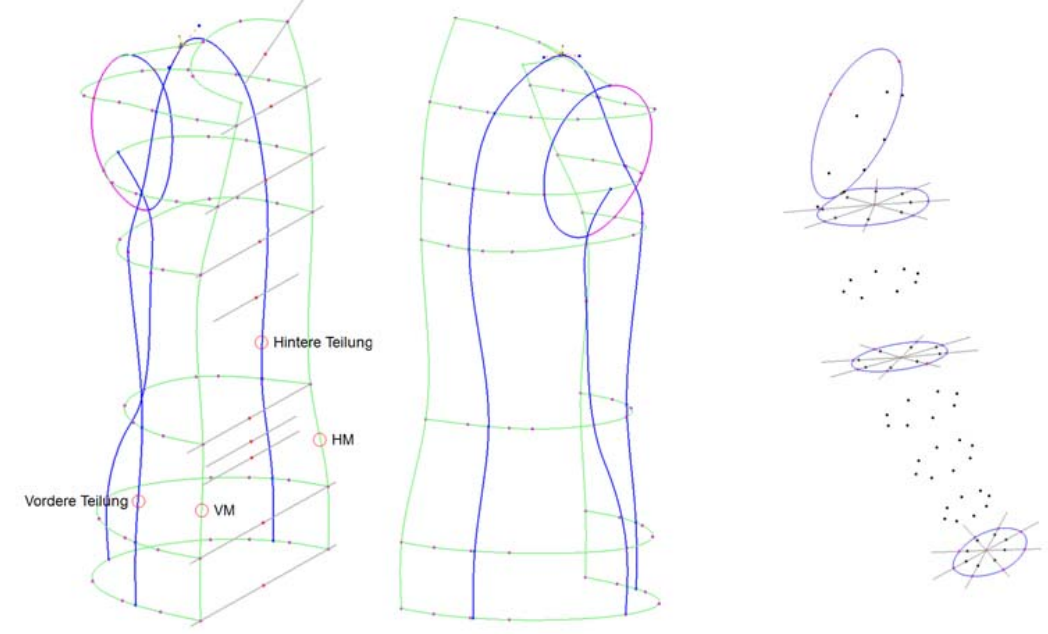

Fig. 8: Scalable construction lines for the blouse 
The size-scalable enveloping surfaces for the garments are divided into pattern parts on the surface by drawing the pattern part curves. It should be noted that surfaces with considerable curvatures resulting from the body shape are divided by dividing lines or darts to get developable surfaces. The 2D pattern parts for the desired body sizes are then computed on the basis of the body shape data, eliminating the usual $2 \mathrm{D}$ grading. To implement the development of freeform surfaces, mathematical algorithms are available [ERM 07], [KRZ 05], [WEE 91], which have found their way into industry-specific commercial software (e.g. Design Concept 3D Lectra [LEC 13], Optitex PDS, from version 11 [OPT 13]).
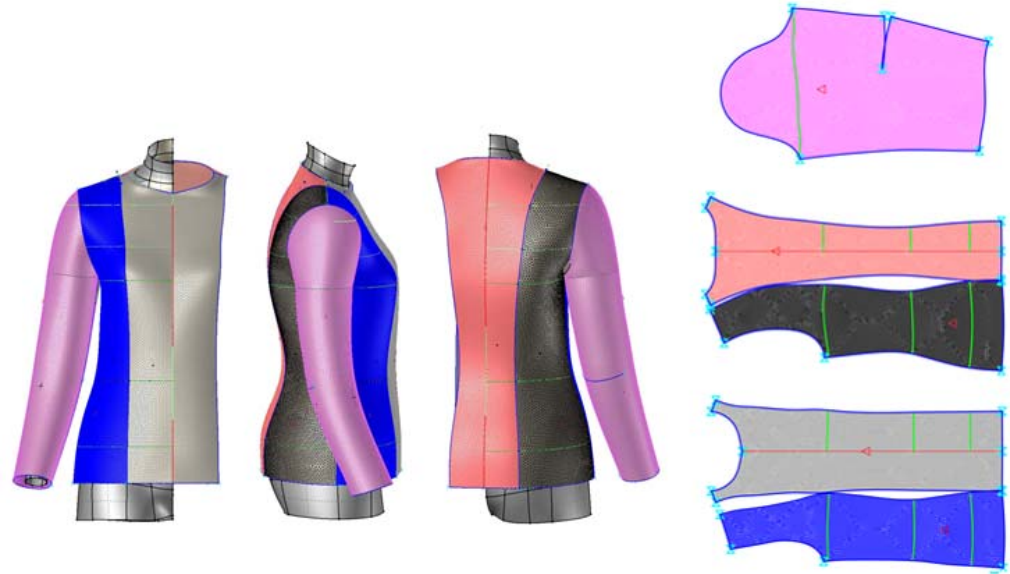

Fig. 9: Left: Blouse construction in 3D, Right: 2D pattern parts

All relevant measured lengths and feature points of the body are automatically projected onto the respective pattern parts. Markings which are required for the subsequent sewing process can also be generated in 3D.
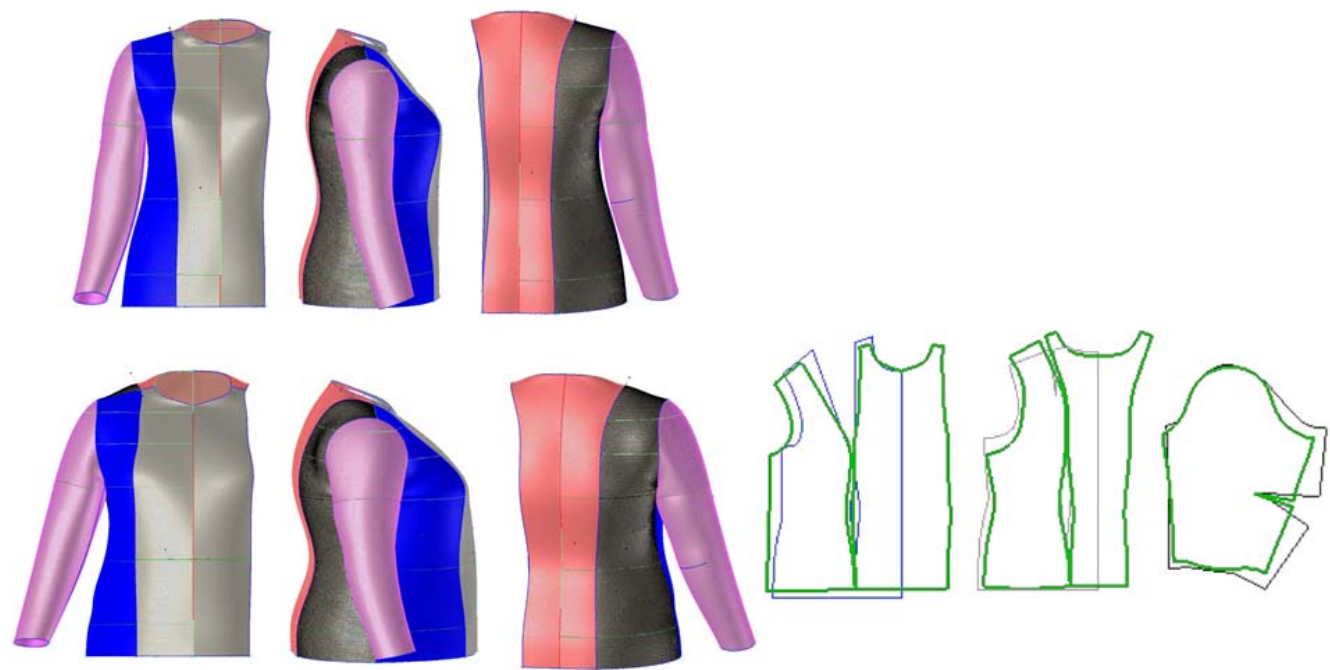

Fig. 10: Left: Blouse construction in $3 D$, right: $2 D$ pattern parts

Fig. 10 shows the blouse models generated in a computer operation in the German sizes 46 and 54 in comparison with the resulting pattern parts of German size 54 produced by grading. Fit testing is currently under way. The presented models were produced based on the assumption that the space between body and blouse should remain the same for all sizes. A computer-aided size modification is possible at any time after fit testing.

\section{Results}

Summarily, it should be emphasised that the construction of the required garment envelope and pattern part definition is only necessary once when scalable mannequins are used. When the mannequin is changed in size, the virtual garment automatically adapts to this change. 


\section{Conclusion}

Up to now the garment pattern making can be accomplished through the empirical experience of the designer because there is a lack of correlation between virtual model and garment pattern. This deficiency can be overcome through direct construction on the virtual mannequin so as to rationalise the product development significantly.

The desired research outcomes will provide an indispensable basis of an effective new technology for the fit-relevant construction of loose-fitting garments and thus of further acceleration of the textile chain. Based on the results of the research project, it enables optimal garment fitting corresponding to the different body types for the target groups. This leads to increased customer satisfaction, a higher purchase frequency and thus contributes significantly to ensuring the market success in this segment. As product development remains one of the most cost-intensive processes, the targeted mission of modern technology will bring about savings of up to $60 \%$ of the currently necessary labour time.

\section{Acknowledgment}

The IGF research project BG09446/13 of the Forschungsvereinigung Forschungskuratorium Textil e. V., Reinhardtstr. 12-14, 10117 Berlin is funded through the AiF within the programme for supporting the "Industrielle Gemeinschaftsforschung (IGF)" from funds of the Federal Ministry of Economics and Technology (BMWi) by a resolution of the German Bundestag.

\section{References}

[ALD 08] Aldrich, W.: Metric Pattern Cutting for Women's Wear, fifth edition, Blackwell, Pub, Oxford, 2008.

[AND 08] Andreeva, М./Андреева, М.:Инновационная технология визуального параметрического проектирования одежды от 3D модели до готовых лекал и раскладок. Швейная промышленность, Nr. 1, 2008.

[ARM 09] Armstrong, H. J.: Patternmaking for Fashion Design, fifth edition, Pearson Prentice Hall, NJ, 2009.

[ASS 13] http://www.human-solutions.com/group/front_content.php?idcat=214\&lang=1, 2013

[BRO 13] Browzwear. http://www.browzwear.com, 2013.

[ERM 07] Ermanni, P.; Endruweit, A.: Composites Technlogien, Kap. Textile Halbzeuge. S. 1-45, Vorlesungsskript, Eidgenössische Technische Hochschule Zürich, 2007.

[HLA 11] Hlaing, E.C.; Krzywinski, S.; Rödel, H.: Development of 3D Virtual Mod $7 e l s$ and 3D Construction Methods for Garments. 2nd International Conference on 3D Body Scanning Technologies, S. 43-51, Lugano, Schweiz, October, 2011

[HLA 13] Hlaing, E. Ch.: Development of Reproducible Methods of Construction for Loose-fitting Garments on the Basis of 3D Virtual Female Models. Dissertation TU Dresden, Fakultät Maschinenwesen, 2013

[HUA 12] Huang, H.Q.; Mok, P.Y.; Kwok, Y.L.; Au, J.S.: Block pattern generation: From parameterizing human bodies to fit feature-aligned and flattenable 3D garments. Computers in Industry, Volume 63, Issue 7, 09/2012, p. 680-691

[KIM 07] Kim, S.; Park, C. K.: Basic garment pattern generation using geometric modelling method. International Journal of Clothing Science and Technology, 2007

[KIR 95] Kirchdörfer, E.; Reusch, K.; et al.: "Konstruktionsgrundlagen für Damen- und Mädchenbekleidung (Teil A-E) - komplett", Bekleidungstechnische Schriftenreihe Band 51, Forschungsgemeinschaft Bekleidungsindustrie e.V., Köln, 1995.

[KOP 91] Kopp, E.; Rolfo, V.; Zelin, B.; Gross, L.: How to Draft Basic Patterns, fourth edition, Fairchild Fashion \& Merchandising Group, New York, 1991.

[KRZ 05] Krzywinski, S.: Verbindung von Design und Konstruktion in der textilen Konfektion unter Anwendung von CAE. Habilitationsschrift, Fakultät Maschinenwesen, TU Dresden, TUDpress, 2005. ISBN 3-938863-10-2.

[KRZ 13] Krzywinski, S.; Hlaing, E.C.; Rödel, H.: 3D-Hosenkonstruktion auf Basis virtueller, skalierbarer Figurinen für Frauen. Textile Network, 1-2, 2013, S. 27-28.

[KUZ 13] Кузьмичев В.; Сурикова Г. И.; Сурикова О. В.; Гниденко А. В.: Проектирование изделий легкой промышленности в САПР (САПР одежды). ISBN: 978-5-8199-05463, Verlag ИД ФОРУМ, 2013.

[LEC 13] Lectra Modaris 3D Fit. http://www.lectra.com, 2013. 
[LIU 05] LIU, R. P.: Pattern Making Theory \& Technology, China Textile \& Apparel Press, Beijing, 2005.

[LIU 10] Liu, Y.-J.; Zhang, D.-L.; Yuen, M. M.-F.: A survey on CAD methods in 3D garment design. Computers in Industry 61 (2010) 576-593.

[MAT 06] Matiko, M.: Clothing Construction, China Textile \& Apparel Press, Beijing, China, 2006.

[MUE 13] System M. Müller \& Sohn http://muellersohn.com/fachbuecher/schnittkonstruktion.

[NAK 95] Nakaho, Y.: Clothing Construction, Asakura Publishing Co., Ltd., Tokyo, 1995.

[OPT 13] Optitex 3D Runway. http://www.optitex.com, 2013.

[PET 06] Petrak, S.; Rogale, D.: Systematic representation and application of a 3D computeraided garment construction method, Part I: 3D garment basic cut construction on a virtual body model, Department of Clothing Technology, Faculty of Textile Technology, University of Zagreb, Zagreb, Croatia, 2006.

[RÖD 11] Rödel, H., et al.: Entwicklung virtueller 3D-Formkörper für die untere Körperhälfte von Frauen auf Basis von 3D-Scandaten.

Schlussbericht, IGF-Forschungsvorhaben-Nr. 15972 BG, Institut für Textilmaschinen und Textile Hochleistungswerkstofftechnik, Technische Universität Dresden, 2011

[ROS 04] Rosen, S.: Patternmaking: A Comprehensive Reference for Fashion Design, Pearson/ Prentice Hall, NJ, 2004.

[SIZ 13] http://www.sizegermany.de/2013

[STA 91] Stanley, H.: Flat Pattern Cutting and Modelling for Fashion, Stanley Thornes, Cheltenham, England, 1991.

[UNI 13] Unicut-Schnittsystem http://www.textilfachschule.ch/ausbildungweiterbildung/inside/unicut-schnittsystem.html, 2013.

[WAN 02] Wang, C. L.; Wang, Y.; Yuen, M. F.: Featured based 3D garment design through 2D sketches. Computer-Aided Design, 2002, Vol. 35, p. 659-672.

[WEE 91] Weeën, F.: Algorithms for draping fabrics on doubly-curved surfaces. International Journal for Numerical Methods in Engineering 31 (1991), 1415-1426. 